\title{
ETNIA, IDENTIDAD \\ Y PATRIMONIO
}

Eduardo Corona Sánchez.

\section{Resumen}

Se trata de una denuncia relativa a la recuperación de la historia de las etnias indígenas que son consideradas como protagonistas de nuestra historia e identidad nacional, a pesar de encontrarse subsumidas al capitalismo neoliberal, al cual contradicen, por ser parte y producto del modo de producción americano que reproducen en sus formas de vida, conocimientos y cosmogonía, que no pueden o deben ser consideradas al igual que ellas como parte de nuestro patrimonio.

\section{Abstract}

This is a report on the recovery of the history of indigenous groups, which are considered as actors in our history and national identity, despite being subsumed in neoliberal capitalism, which contradict for being part and product of the American Production Mode that played in their ways of life, knowledge and cosmogony, which may or may not be considered like them as part of our heritage.

La fundación del INAH, emitida por ley en 1938, implicaba el trabajo de investigación científica para el conocimiento de los pueblos indios, es decir, se trataba de generar un conocimiento consecuente a una política de investigación identificado con su conocimiento, caracterización y cambio social de las etnias del México indígena.

Esta consigna no solo fue expresión de un régimen comprometido con un movimiento social que daba respuesta al mandato del propio movimiento, es decir, del sacrificio de más de 5 millones de gentes que buscaron en la Revolución mexicana 
la concreción del alzamiento independiente para fincar en los propios principios históricos de México como nación en su desarrollo capitalista, lo que implicaba el derecho a definir su soberanía política con relación a una historia de 500 años de dominación que había traído como consecuencia la marginación de las etnias en el desarrollo del país, y que se traducía en la existencia de dos Méxicos, el México indígena y el México capitalista, incluidos en su esencia de formación socioeconómica multiétnica y pluricultural.

La inclusión del México indígena, mesoamericano, en la historia universal, fue el resultado de una empresa mercantilista que, a través de la conquista y la colonización, subsumió de manera formal e informal ${ }^{1}$ a los denominados pueblos indios al desarrollo del capitalismo.

Si bien, la subsunción histórica de los pueblos indios se traduce en la articulación asimétrica de modos de producción diferentes como parte de la estrategia colonial para sostener a las empresas mercantilistas y permitir la reproducción ampliada del capital, a través de la enajenación de sus tierras y trabajo, como producto no solo de la esclavitud y muerte masiva, sino también la marginación y empobrecimiento de la población indígena, dentro de una política racial que actualmente a pesar de 300 años de independencia y 200 años después de una rebelión social contra los resabios colonialistas, continúa todavía una situación de colonialismo interno sobre los grupos étnicos, que implica el despojo, la masacre y su trato como el Otro, sin considerar incluso sus derechos ante las leyes como ciudadanos.

La burguesía dominante no ha sido capaz de aceptar que somos una sociedad pluriétnica y multicultural, en donde todos tenemos los mismos derechos, no solo prebendas con referencia a la distribución del capital, sino derechos históricos de identidad nacional, por haber actuado en el proceso histórico de desarrollo de este

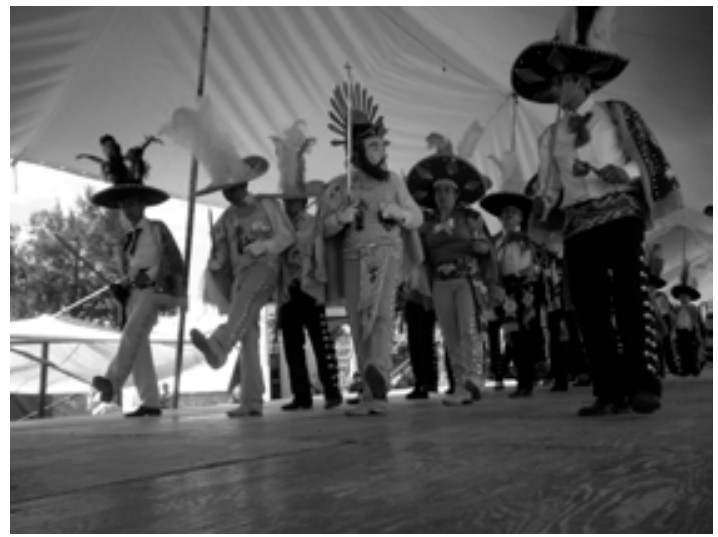
país y de caracterizarlo.

Los grupos étnicos de México, no solo fueron la mano de obra en las minas, los obrajes, las haciendas, los ingenios, los trapiches y los batanes, sino también los responsables del arte manual, del arte tequitqui o indoamericano de objetos artesanales y responsables como agricultores del sostenimiento económico de los poblados, así como de la mano de obra de la construcción de templos y las grandes ciudades que aunque por el sentido colonialista, reproducen en América a las metrópolis y provincias hispanas,

\footnotetext{
1 MARX. Karl, VI. Inédito. Siglo xxi Editores.
} 
como Antequera, Vallalodid, Guadalajara, Salamanca, etc. Sabemos que nacen en función al tributo en trabajo de los pueblos indios, o bien sustituyen o reproducen en la traza y ubicación de sus edificios la identidad mesoamericana (ver Foto).

México, como país mestizo y multicultural, expresa en su conformación como nación un alto nivel de identidad indígena, que se hace hoy por hoy evidente en el aspecto físico de la mayoría de sus pobladores, en su alimentación o costumbres culinarias, en sus formas de hablar el castellano, en su concepción del mundo inserta su cosmogonía sincrética, en sus hábitos de conducta en sus tradiciones festivas que siguen el calendario agrícola determinado por el cultivo del maíz, con relación a sus formas de uso racional de la naturaleza y en muchos aspectos más que son producto no de una historia de 200 o 500 años sino de más de cinco mil, por eso las comunidades étnicas son las que más dan la pelea a la política neoliberal.

Así sabemos, por la contrastación etnológica con otros grupos étnicos contemporáneos de recolectores cazadores ${ }^{2}$ que los primeros pobladores que se introducen de entre 30000 y 20000 años por el estrecho de Bering, eran sociedades igualitarias con sistemas de parentesco de identidad exogámica y unilineal ${ }^{3}$, que les permitió apoderarse de la megafauna para su sobrevivencia y que además de ocupar gran extensión del continente, se enfrentaron a cambios climáticos drásticos debidos al movimiento de los deshielos causados por las glaciaciones lo que ocasionaron la formación de grandes áreas de desierto, que condujo al desarrollo de industrias líticas propias, dentro del modo de producción de la sociedad primitiva ${ }^{4}$.

Sin embargo, hace 6000 a.n.e., otra corriente poblacional se introduce tal vez por el Pacífico, la cual, aunque también de origen asiático, no era de igualitarios sino estamentarios con una escala definida con relación a su ancestro común además de exógamos y bilaterales ${ }^{5}$, fórmulas de organización que les permitió experimentar en la naturaleza como si fuera un verdadero laboratorio ${ }^{6}$, así es a través de la interacción de esos grupos con la naturaleza, como se generan formas de apropiación y alteración del medio ambiente, que conducen a la domesticación de un gran número de plántulas debido a un uso múltiple y diferenciado de sus diversos ecosistemas de desierto, montaña, pantano y selva; particularmente las selvas de tipo tropical húmedo que como las de Chiapas constituyen un escenario más complicado y difícil de explotar por su bioregeneración intensiva, pero que fueron domesticadas desde hace más de tres mil años por los Maya y Olmeca.

La dispersión de estos grupos por el continente se sucede a través de diferentes corrientes étnicas que han sido detectadas y definidas por la lingüística, como

\footnotetext{
2 KIRCHHOFF, Paul; Los principios del clan en la sociedad humana. Washington D.C. Morthon Fried y Cronwel H, York editors. 1968. Vol. II. pág.18.

3 KIRCHHOFF, Paul; Op. cit.

$4 \quad$ Roger Bartra o Bate.

5 KIRCHHOFF, P. Op. cit.

6 MARX, Karl; El método en la economía Politica. México 1971. Editorial Grijalbo S.A. pp. 112-113.
} 
familias Macro Maya, Macro Quechua, Macro Otomangue y Uto-Nahua ${ }^{7}$, entre las más antiguas que se distribuyen ocupando los diferentes y complejos espacios geográficos y ecológicos de identidad americana.

Así, al igual que sucedió con otros grupos de esta identidad clánica cónica que ocuparon el continente ${ }^{8}$, en Mesoamérica se fue conformando un modo de producción propio de identidad americana continental, que fue capaz de llegar a la formación de Estados, sin pasar por el esquema evolutivo y la historia de las sociedades asiáticas, mediterráneas y europeas, correspondientes a otros modos de producción?, que condujo al desarrollo formaciones sociales aldeanas, centros ceremoniales y ciudades-estado e incluso imperios antiguos de identidad clasista.

Sabemos que aquí en Mesoamérica, es el hombre la única fuerza productiva, capaz de transformar la naturaleza para construir ciudades y civilizaciones y fue a través de distintas fórmulas étnicas que se generan diversas técnicas y estrategias de apropiación adecuadas a los diferentes ecosistemas que presentaba Mesoamérica con base a formas sociales de trabajo corporativo producto de relaciones sociales comunitarias y a su articulación interétnica e interregional —a veces asimétrica - en su proceso de desarrollo, que se amplió la capacidad de producción ${ }^{10}$.

Así, el integrarse históricamente diferentes regiones ecoétnicas dentro de un área mayor, condujo a la formación de un modo de producción común, americano, diferenciado en sus expresiones étnicas. Si bien todas las etnias mesoamericanas viven de ciclos productivos del maíz y de tubérculos, y elaboran cerámica, arquitectura y escultura, estas se elaboran con estilos propios identificados con las etnias, asociadas también a diferentes formas de expresión lingüística o dialectal, pero que se inscriben dentro del mismo sistema, iconográfico o ideográfico, y esto se debe a que tuvieron formas comunes de tenencia de la tierra y de trabajo ligados a unidades corporativas territoriales como unidades sociales de producción y sistemas conceptuales del universo, vinculados a un calendario agrícola que articulaba al hombre con la naturaleza, con la sociedad y con la cosmogonía como un todo ${ }^{11}$.

Así, el área cultural mesoamericana se conforma por una serie de etnias producto del mismo modo de producción americano, que ubicadas en diferentes ecosistemas, desarrollan diferencias que los señalan y reinterpretan en su definición, como formaciones sociales, las cuales compiten entre sí o se confederan y se expanden para articular diferentes ecosistemas y formulas de producción que aumentan y diversifican sus fuerzas productivas y complementan su economía dentro de un régimen

\footnotetext{
7 CAMPBELL, Lyle; "Retos en la clasificación de las lenguas Indígenas de México" México 2007. pp13-67.

8 CORONA, Eduardo. "La integración de las áreas en el Modo de Producción Américano”. México. INAH.2003. La etnohistoria de México. Colección Científica. No.529.

$9 \quad$ MARX, Karl; Op.Cit. pp. 120-144.

10 CORONA, Eduardo; "Sobre el nivel de desarrollo de las fuerzas productivas en Mesoamérica”. Merida Yucatán 1978. Boletín Ecaduy.

11 CORONA, Eduardo; "El Factor étnico en las relaciones sociales de producción en Mesoamérica” Mérida, Yucatán 1985, Boletín Ecaduy. pp.37- 48.
} 
tributario que conduce a veces a revoluciones que significan el cambio del poder de una región a otra con una formación étnica diferente o dentro de la misma, que con las experiencias acumuladas marcan también las diferentes etapas de evolución del modo de producción americano.

Esas etnias mesoamericanas, que después se integran como "pueblos de indios" al servicio de las empresas coloniales del mercantilismo hispano, son las que aunque con restricciones europeas, siguieron expresando su propia identidad étnica correspondiente al modo de producción americano, como regiones Totonaca, $\mathrm{Na}$ hua, Zapoteca, Mixteca, Maya, Tzeltal, Tzoltzil o Tojolabal, etc., con población agrícola dispersa en pequeños poblados, en donde siguen respondiendo a sus formas de vida y a su ecología y medio ambiente. Así, las etnias indígenas de identidad americana, siguen siendo hasta finales del siglo XIX la población mayoritaria y sus formas de identidad étnica son las que los mantienen unidos e integrados como grupo ante la historia de un país que navegó en el capitalismo a nivel periférico, y no fue sino a partir de la Revolución mexicana, en término de cambios de leyes más democráticas, que una gran parte de estas poblaciones se subsume con mayor intensidad a la formación de las ciudades y provincias del México contemporáneo, con una identidad somática más indígena que mestiza, pero también frecuentemente más empobrecida.

La identidad mesoamericana de la población étnica indígena no se pierde, se subsume $^{12}$; a veces de manera formal y se integra al desarrollo capitalista o de manera informal y se continúa el modo de producción americano que subsumido evoluciona, y ahora en los albores del siglo XXI siguen siendo la base de nuestra identidad y de nuestra ideología nacionalista a nivel histórico. Aunque de hecho constituyen la población más marginada, continúa su abuso y explotación, como fuerza de trabajo; y en cuanto a derechos e igualdad social, siguen siendo marginados y desposeídos de sus recursos, de su tierra y de sus productos. De hecho, se trata de una subsunción histórica asimétrica de modos de producción la que ha permitido dentro del desarrollo capitalista, la explotación de las etnias por una sociedad sin identidad étnica o bien de identidad extranjera inglesa o norteamericana, que sigue enajenándolo de sus medios de producción para acumular riqueza dentro de fórmulas de reproducción ampliada del capital ${ }^{13}$.

Sin embargo, son sus fórmulas de resistencia el retener su propio territorio, su lengua y su cultura, como formas de identidad histórica propia, lo que les permite seguir sobresaliendo a pesar de la política neoliberal que insiste en enajenarlos de su tierra y de sus formas de vida para transformarlos en el ejército de reserva de empresas de capital nacional y extranjero. Se sucede, sin embargo, una subsunción informal que le permite reproducirse dentro de este neoliberalismo con sus propias tradiciones de trabajo y producción, acorde al modo de producción americano, expresado en su economía, sus relaciones sociales y su cosmogonía articuladas, lo que conduce a

\footnotetext{
12 MARX, Karl; El Capital. "Libro I". pp. 54-77.

13 PALERM, Ángel; Antropología y Marxismo. México 1981. Centro de Investigaciones superiores del INAH. Editorial Nueva Imagen. pp.70-82.
} 
la reproducción de sus formas sociales y que se elaboren productos agrícolas y artesanales, que se introduzcan al mercado capitalista en donde retroalimentan su identidad mesoamericana, expresada a través de sus materias primas o de sus formas de concepción del color y de diseño, evidenciados en artesanías: telas, máscaras, collares, adornos, etc. ${ }^{14}$; que se reinterpretan como lo mexicano.

Porque la identidad étnica indígena no es una credencial de referencia que permite identificar a una persona por su lengua o por su indumentaria, es una forma de vida producto de una tradición histórica ancestral, en donde están en juego sus fórmulas de trabajo de la tierra para la continuidad de las formas de vida del grupo, de uso de la naturaleza, de su uso medicinal y su uso ideológico con relación al ciclo de vida del hombre. Es una forma de trabajo en donde la familia se une a través de lazos de parentesco relacionados con la tierra y con la producción, en donde los parientes, la esposa y los hijos constituyen una unidad social corporativa de trabajo y producción, en la cual la ideología va de la mano con el ciclo agrícola de la naturaleza y el ciclo de vida del hombre. En donde los rayos, el trueno, el crecimiento de las flores, el graznido de las aves, el movimiento de la luna, la posición de los astros, el cambio de clima, su entorno, sus cuevas, sus cuesillos, los montículos, sus cerros o zonas sagradas están asociados al acontecer humano y constituyen su patrimonio, como recurso social histórico y mítico, lo cual permite la reproducción de su identidad como grupo social y como etnia.

Debemos reconocer que para estos momentos, con una política neoliberal del Estado y dentro de un colonialismo interno es el hombre de ciudad el que marca su sino o su destino, lo enajena de su historia, invade sus tierras pues no se identifica con su identidad, en consecuencia se incide en la pérdida de sus propiedades muchas veces comunales, de sus creencias y de las formas de vida indígena, que incluso los obliga a emigrar al extranjero en donde justo la reproducción de sus formas de identidad étnica constituyen su fuerza de ayuda mutua y de identidad corporativa, aunque a veces estas instancias se subsunen formalmente y desaparecen.

Por otra parte, como lo hemos planteado, las formas de identidad étnica, tradicional, campesina o indígena, se convierten cada vez más en consecuencia de la política mercantilista neoliberal, capitalista a ultranza, en un estigma de pobreza extrema ${ }^{15}$. E incluso se le acusa de ignorancia y calificado como sinónimo de retraso, por su identidad histórica con el pasado, como si se trataran de algo fuera de la realidad, como un objeto de vitrina y de exhibición en los museos, sin derecho a caminar por las calles de los pueblos mestizos y castizos que corresponden a otra historia, la globalizante y enajenante.

Gentes que fueron parte de la historia indígena, se insertan ahora en la historia urbana, en el proceso de construcción urbana de las metrópolis como fenómeno

\footnotetext{
14 GARCÍA, Néstor; Culturas populares en el capitalismo. México 2002. Editorial Grijalbo.

15 ALARCÓN, Pablo; "Riqueza ecológica versus pobreza social, contradicciones y perspectivas del desarrollo indígena en Latinoamérica”. Buenos Aires 2006. En: Pueblos indigenas y pobreza, enfoques multidiciplinarios, CLACSO-CROP. pp.41-69.
} 
social y cultural ${ }^{16}$ de las ciudades periféricas a la gran urbe, que se vuelven receptáculo de los migrantes producto de un capitalismo a ultranza y en crisis que sigue cumpliendo las fórmulas de reproducción ampliada del capital. Así, como consecuencia de haber perdido sus tierras o la capacidad productiva de sus tierras, ciudades en donde copian los hábitos europeos, pierden el uso de su lengua y no siempre la reproducen con sus hijos, los cuales se inscriben formalmente como parte de la ciudad, en donde a veces solo conservan sus relaciones de parentesco familiar y algunas tradiciones de identidad étnica que se van perdiendo, aunque algunas veces se retroalimentan y amplían o transforman, identificándose con una calle de una colonia o un departamento, sin conocer a sus vecinos pero sí reconocen a gente de su propia identidad étnica, y logran establecer una correlación de compañerismo y solidaridad con gente de su barrio, su colonia o su delegación, identificándose incluso con formas de organización grupal que se reproduce en sus ritos y en sus mitos.

Sin embargo, otros más se subsumen formalmente en una historia aprendida en libros que se impone como una fórmula de identidad nacional, con nombres y sitios que no corresponden a su región, con un sistema educativo que implica la pérdida sistemática de su lengua para dirigirlos hacia los mitos reconstruidos por el Estado para reproducir según se plantea en los nuevos planes de estudio, la memoria de un país en formación con una historia de 100 o 200 años, en el cual frecuentemente se olvida que es profunda y antigua de más de 5000 años de evolución, que la identifican como formación social e histórica propia y única a nivel universal.

En cambio, la identidad étnica en las comunidades indígenas se adquiere desde que se nace y se aprende en la familia, en el pueblo, en el trabajo, en la interacción con la naturaleza, en las tradiciones, en los cantos y en los mitos; se reproduce también con la historia oral, con las tradiciones que se repiten y reproducen día a día, en la vida de ciclo y muerte de los miembros de la comunidad, del ciclo de fiestas, que se reproduce y mitifica en las anécdotas y en los cuentos de los nahuales y de los muertos, de los animales y de las plantas, de las montañas sagradas o no y de los ríos, que conforman el paisaje que es el mundo de referencia de la vida y del ciclo humano, de una historia que se ubica en un espacio concreto, en un momento en que sucedió algo en el cielo o en la tierra, como parte de la explicación de la vida del ser humano, que las une e interpreta como propias, por ser parte y producto de un espacio y tiempo amplio pero concreto, como un hilo conductor, un contexto que permite saber quién se es, no solo un nombre sino un ser humano, identificado con un terruño, con la historia de un lugar, con un lugar de un territorio, con una familia, con un pueblo, con una sociedad, con una historia de la que forma parte y es producto.

Todo ello es una identidad patrimonial, una historia que se junta con otras historias, en lugares que se explican con base a un largo y antiguo pasado, en donde el pueblo cuenta como parte de una célula en un organismo mayor de la cual forma

16 GIGLIA, Ángela; "Reflexiones sobre el concepto de habitar y la producción de la ciudad en el oriente de la zona metropolitana de la ciudad de México" México. 2007. En: Conurbados e imaginarios urbanos. pp.25-54. 
parte a través de esa profundidad histórica, de unas raíces que se extienden en un espacio más amplio que nutre y genera también la historia de la nación.

Esto es lo que les da derechos, es lo que permite exigir el mismo trato, es lo que se denuncia y por lo que se pronuncian los pueblos étnicos, es por ser parte de esa historia y por lo tanto obtener respeto y significado con relación a todos los demás, es una forma de defender lo propio como parte de la comunidad, es ser y ser parte del todo, es lo que da referencia histórica, concreta de la identidad pluriétnica y multicultural de un país ${ }^{17}$, que gracias a ello se expresa como nación.

Etnia y patrimonio van unidos a nuestra historia, pero no son las etnias nuestro patrimonio, sino su historia, su acción y su obra, sus expresiones y sus denuncias, que están presentes en nuestra historia y la permean. La etnia tiene derechos como parte de una totalidad social (de la cual es parte y producto); derechos, no concesiones o condiciones, pues no se le puede conceder a la etnia que se exprese y viva como tal y no como nosotros, eso es parte de su esencia y de su historia y se debe de respetar y garantizar su continuidad. Así, en consecuencia la etnia indígena genera su patrimonio tangible e intangible, como resultado de sus formas de vida y de su identidad como grupo con su historia y con su ideología; es lo que le permite reproducirse e integrarse con los demás, y estas formas de vida y expresión continua se deben de acrecentar pues nutren a la identidad nacional y en consecuencia a nuestro patrimonio cultural.

Las nación se nutre a través del patrimonio que se crea a partir de la identidad y de la historia de los pueblos, de la integración de estos a través de la historia y de la toma de conciencia del valor de ellos como parte de nuestra identidad, etnia patrimonio y nación, son valores y categorías que no están separadas, que se unen como parte de un proceso histórico y que constituyen la fuerza de una formación social, su idiosincrasia, su identidad en un plano internacional, lo cual les permitiría ubicarse como protagonista de nuestra historia, compartirla con los otros grupos sociales que también nos constituyen, para contribuir al desarrollo nacional y continuar la evolución de México como formación socioeconómica.

Las etnias de México siguen interviniendo en la historia de país, son nuestra expresión de respuesta al neoliberalismo, son la respuesta a la sociedad civil que encuentra en ellas una explicación de su identidad y de sus formas de vida, son no solamente indispensables sino trascendentales en la historia de la nación mexicana.

Es por ello, que en este momento, cuando contrastamos la realidad histórica de nuestra identidad étnica indígena, proponemos al igual que ellos una defensa a ultranza de nuestras raíces y de nuestro patrimonio ante el embate neoliberal.

17 BARTOLOMÉ, Miguel y BARRABÁS, Alicia; La pluralidad en peligro. Procesos de transfiguración y extinción cultural en Oaxaca (chochos, chontales, ixcatecos y zoques). México 1999. Instituto Nacional de Antropología e Historia. Instituto Nacional Indígenista. 


\section{BIBLIOGRAFÍA:}

BARTOLOMÉ, Miguel Alberto y BARABAS Alicia Mabel.

1999 Lapluralidad en Peligro. México. Instituto Nacional de Antropología e Historia. Instituto Nacional Indigenista.

1998 Autonomías étnicas y Estados Nacionales. México Instituto Nacional de Antropología e Historia.

CAMPBELL, Lyle Richard.

2007 Retos en la Clasificación de las Lenguas Indígenas de México. México. Memorias del III Coloquio Internacional de Lingüística Mauricio Swadesh. UNAMIIA-INAH.

CIMADAMORE, Alberto D.; EVERSOLE, Robyn y MCNEISH. John-Andrew

2006 Pueblos Indígenas y Pobreza. Buenos Aires Arg.CLACSO. Libros.

CORONA SÁNCHEZ Eduardo

1978 Sobre el Nivel de desarrollo de las fuerzas productivas en Mésoamérica. Mérida. México. ECADUY.

1985 El factor étnico en las relaciones de producción, Mérida México. Boletín del ECADUY.Año.5. No.29 pp. 37-48.

2003 La Integración de áreas en la conformación del modo de producción Americano en la Etnohistoria de México. México.INAH. Colección Científica.

HERRERA BAUTISTA, Martha Rebeca y MOLINA, Paulina

2009 Creciendo en la adversidad. México. Juan Pablo Editores.

MARX, Carlos

1971 El Método en la economía política. México. Editorial Grijalbo.

MARX, Karl

1985 El capital Libro I.Capitulo VI Inédito. México. Siglo xxi Editores.

KIRCHHOFF, Paul.

1968 Los principios el clan en la sociedad humana. Washington D.C. Morthon Fried Thomas y Cronwel H. York. Editores.Vol.II.18.p.

PALERM, Angel

1982 Antropología y Marxismo. México. Centro de Investigaciones Superiores del INAH. Editorial Nueva Imagen.

Pronunciamiento,

2001 Propuestas Conjuntas que el Gobierno Federal y el E ZLN se comprometen a enviar a las instancias de debate y decisión nacional. Nurio Michoiacan. México. A.I.P.I.N. Agencia Internacionasl de Prensa India.

SÁNCHEZ ALANIZ, José Ignacio y GURROLA BRIONES, Susana.

2004 El uso social del patrimonio cultural. México.Ediciones Quinto Sol.

SWADESH, Mauricio

1969 Un nexo prehistórico entre quechua y tarasco, México. Anales, septima época Tomo I. pp.127-138 
TEJERA GAONA, Hector

1996 Antropología Política, enfoques contemporáneos. México, Plaza y Valdes, Instituto Nacional de Antropología e Historia

TORRES DE ARAUZ, Reina

1971 Patrimonio Histórico. Panamá R. de P. Revista de la Dirección del Patrimonio Histórico. Instituto Nacional de Cultura y Deportes. 